\title{
"Getting to Know Me": The development and evaluation of a training programme for enhancing skills in the care of people with dementia in general hospital settings
}

Ruth Elvish ${ }^{1}$, Simon Burrow ${ }^{1}$, Rosanne Cawley ${ }^{1}$, Kathryn Harney ${ }^{2}$, Pat Graham ${ }^{3}$, Mark Pilling ${ }^{1}$, Julie Gregory ${ }^{1}$, Pamela Roach ${ }^{4}$, Jane Fossey ${ }^{5}$, and John Keady ${ }^{6}$

${ }^{1}$ School of Nursing, Midwifery, and Social Work, University of Manchester, ${ }^{2}$ Greater Manchester West Mental Health NHS Foundation Trust, ${ }^{3}$ Royal Bolton Hospital NHS Foundation Trust, ${ }^{4}$ Department of Family Medicine, University of Alberta, ${ }^{5}$ Oxford Health NHS Foundation Trust, ${ }^{6}$ School of Nursing, Midwifery, and Social Work, University of Manchester/ Greater Manchester West Mental Health NHS Foundation Trust.

\section{Address for correspondence}

Dr Ruth Elvish

Dementia and Ageing Research Team

School of Nursing, Midwifery and Social Work

University of Manchester

University Place

Oxford Road

Manchester

M13 9PL

UK

Tel: +44 (0)161 3067854 (Direct Line)

Fax: +44 (0)161306 7894

Email: ruth.elvish@manchester.ac.uk 


\title{
"Getting to Know Me": The development and evaluation of a training programme for enhancing skills in the care of people with dementia in general hospital settings
}

\begin{abstract}
Objective: The aims of the study were to report on the development and evaluation of a staff training intervention in dementia care designed for use in the general hospital setting: the "Getting to Know Me" training programme. The study also aimed to undertake initial psychometric analysis on two new outcome scales designed to measure knowledge and confidence in dementia care.
\end{abstract}

Methods: The study comprised two phases. The first phase comprised the design of two questionnaires which are shared within this paper: Confidence in Dementia (CODE) Scale and Knowledge in Dementia (KIDE) Scale. In phase two, staff undertook the "Getting to Know Me" training programme $(n=71)$. The impact of the programme was evaluated using a pre-post design which explored: i) changes in confidence in dementia; ii) changes in knowledge in dementia; and iii) changes in beliefs about challenging behaviour.

Results: The psychometric properties of the CODE and KIDE scales are reported. Statistically significant change was identified pre-post training on all outcome measures. Clinically meaningful change was demonstrated on the CODE scale.

Conclusions: The "Getting to Know Me" programme was well-received, and had a significant impact on staff knowledge and confidence. Our findings add to a growing evidence-base which will be strengthened by further robust studies, the exploration of the impact of staff training on direct patient outcomes, and further identification of ways in which to transfer principles of care from specialist dementia environments into general hospital settings. 


\section{"Getting to Know Me": The development and evaluation of a training programme for enhancing skills in the care of people with dementia in general hospital settings}

\section{Introduction}

Dementia is a syndrome which is characterized by a decline in cognitive functions (National Institute for Health and Clinical Excellence, 2007), and there are currently around 800,000 people with dementia in the United Kingdom (Department of Health, 2010). It is estimated that 25 per cent of hospital beds are occupied by people with dementia over the age of 65 (Alzheimer's Society, 2009), and a stay in hospital is likely to be longer for a person with dementia than for others admitted for the same procedure. The National Institute for Health and Clinical Excellence and Social Care Institute for Excellence (2007) recommend that acute hospital services are reviewed in order to promote independence and maintain function of people with dementia. Objective 8 of the National Dementia Strategy in England (Department of Health, 2009) highlights the lack of leadership for dementia care in general hospitals, and acknowledges that senior clinicians should take lead roles for the improvement of dementia care in these settings. Improved quality of care in general hospitals was subsequently highlighted as one of four key priorities in the Department of Health's revised implementation plan for the National Dementia Strategy (Department of Health, 2010).

A report by the Royal College of Psychiatrists (2011) suggests that there is no mandatory dementia training in $95 \%$ of hospitals in England. A number of studies have found that staff are regarded as friendly and hard working, but they are not equipped to work with people 
The "Getting to Know Me" training programme

experiencing dementia and they do not have the specific skills to do this effectively (Cowdell, 2010). Staff members themselves acknowledge that they need improved knowledge and education about dementia (Dunbar and Gardiner, 2007), and Galvin, Kuntemeier, AlHammadi, Germino, Murphy-White and McGillick (2010) found that the greatest unmet need amongst acute hospital staff caring for people with dementia was in-service training in dementia care.

Whilst the present study focuses on dementia training for general hospital staff, it is helpful to note what it known about training for staff within specialist dementia long-term care settings. Despite the wide-use of training programmes, the evaluation of their impact has proved challenging. Although many studies report positive findings (eg. Innes, 2000), methodological limitations such as lack of a control group, non-calculation of effect sizes, insufficient blinding, and variability in the nature of interventions and target outcomes make it difficult to draw strong conclusions (McCabe, Davison and George, 2007). Comparisons across studies is also a challenge as there are few good quality outcome measures (Kuske, Hanns, Luck, Angermeyer, Behrens and Riedel-Heller, 2007), a range of domains are measured across studies, and there is a lack of agreement about which outcome measures should be used (Moniz-Cook et al., 2008). Moniz-Cook et al. (2008) call for the continued development of good quality outcome measures, and Schepers (2010) highlights that there are few measures for positive capacity in staff, that are appropriate for frontline and unqualified staff, and that report psychometric properties. Regarding which domains are important to measure, Bandura (1977) argues that beliefs about personal self-efficacy determine effort and coping behaviours in challenging situations, thus suggesting that confidence is likely to be an important factor in staff behaviour. Consistent with this, 
The "Getting to Know Me" training programme

Zimmerman et al. (2005) argue that there is a link between perceived competence and positive attitudes towards dementia. Level of knowledge is argued to be linked to confidence (Hughes, Bagley, Reilly, Burns, \& Callis, 2008), thus suggesting that measuring knowledge is also important. Regarding mode of delivery, most training programmes recommend didactic sessions followed by either follow-up sessions or experiential learning (eg. Davison, McCabe, Visser, Hudgson, Buchanan, \& George, 2007; Teri, Huda, Gibbons, Young, \& van Leynseele, 2005). At present, a strong case can be made for the use of training programmes for specialist dementia care staff, but it is acknowledged that further high quality studies are needed. Not surprisingly, a strong evidence base has also yet to be developed for the impact of staff training on the care of people with dementia within the general hospital. However, one promising finding is from work by Galvin et al. (2010). Their study found that a seven hour training programme led to immediate improvements in staff knowledge and confidence in dealing with people with dementia in hospital, an improvement which was largely maintained after four months.

The work discussed in the introduction to this paper provides a foundation on which to build the present study. The aims of the present study were therefore to: i) develop the "Getting to Know Me" dementia training programme for use with general hospital staff; ii) develop outcome measures with good psychometric properties to measure staff confidence and knowledge; iii) evaluate the impact of the "Getting to Know Me" programme. 
The "Getting to Know Me" training programme

\section{Methods}

The study was given a favourable opinion by Lancaster ethics committee, and approval to undertake the project was given by Royal Bolton Hospital NHS Foundation Trust Research and Development Office.

\section{Overview}

The study adopted classical test construction methods to design two psychometrically sound questionnaires which are shared within this paper: Confidence in Dementia (CODE) Scale and Knowledge in Dementia (KIDE) Scale. A pre-post design assessed changes following completion of the "Getting to Know Me" training programme in: i) confidence in working with people with dementia; ii) knowledge in dementia; and iii) beliefs about behaviour that challenges. Outcome measures were administered at two time points: immediately before the training (time point one) and directly after the training had been completed (time point two).

\section{Participants}

Participants were required to be staff members working within a North-West general hospital on one of six wards (including complex care, trauma orthopaedic, and orthopaedic wards) on which the majority of people being cared for were over 65 . The hospital involved in the project was selected on a pragmatic basis following calls for expressions of interest to implement training in dementia care. The selected wards were those identified within the hospital as providing care predominantly for older people. 
The "Getting to Know Me" training programme

\section{Scale development and outcome measures}

Confidence in Dementia Scale: This new nine-item self-report questionnaire was used to measure confidence in working with people with dementia. Using ideas from a range of existing measures, the scale was developed by three of the authors (RE, SB \& JK), who have expertise in the field of dementia care. One hundred and fifteen participants completed the scale. The Kaiser-Meyer-Olkin (KMO) measure of sampling adequacy assesses whether the sample size is sufficient relative to the number of items in the scale. The KMO if an item was deleted was above 0.8 for each item; this represents good sample adequacy (Pett, Lackey and Sullivan, 2003), and resulted in the retention of all nine items on this scale (Table 1). The questionnaire was scored on a five point Likert scale with anchored ratings of 'not confident', 'somewhat confident', and 'very confident'. This meant that it was possible to gain a total score between 9 and 45, with a higher score representing better confidence in working with people with dementia. The Cronbach alpha value was 0.91 and the overall $\mathrm{KMO}$ was 0.90 , suggesting that the scale had good internal consistency without too much item redundancy (Nunally, 1978; Streiner and Norman, 2003). Discussion between the authors regarding the items within the scale suggested that the scale had adequate face validity. The process of calculating KMO when a variable is deleted and alpha when a variable is deleted, in addition to discussion between authors, also suggested that the scale had good content validity.

Knowledge in Dementia Scale: This new 16-item self-report questionnaire was used to measure knowledge in dementia. Initially, 27 items were developed using an existing 
The "Getting to Know Me" training programme

questionnaire (Fossey et al., 2006) by three of the authors (RE, SB \& JK). One hundred and fifteen participants completed the original 27-item questionnaire (Fossey et al., 2006). Through examination of the KMO if any item deleted, a separation of values was noted at a point of 0.55 . This led to a pragmatic choice to retain items above 0.55 , meaning eleven items were removed to leave a revised 16 -item version of the questionnaire (Table 2). The questionnaire was scored on an agree/disagree scale; 'agree' responses were given a score of 1 , 'disagree' responses were given a score of 0 . This meant that it was possible to gain a total score between 0 and 16, a higher score being representative of better knowledge about dementia. The Cronbach alpha value for the scale was 0.72 and the overall KMO was 0.70 , suggesting that the scale had good internal consistency and reasonable sample adequacy (Nunally, 1978; Pett et al. 2003). Discussion between the authors regarding the items within the scale suggested that the scale had adequate face validity. The process of calculating KMO when a variable is deleted and alpha when a variable is deleted, in addition to discussion between authors, also suggested that the scale had good content validity.

Controllability Beliefs Scale: This 15-item self-report questionnaire was used to measure staff beliefs about the controllability of behaviour that challenges. The scale is based on the theory that attributions of controllability determine staff responses. The questionnaire is measured on a five point scale with anchored ratings of 'agree strongly', 'agree slightly', 'unsure', 'disagree slightly', and 'disagree strongly'. Cronbach's alpha for the scale is 0.89 , suggesting a high degree of internal consistency (Dagnan, Grant and McDonnell, 2004). 
The "Getting to Know Me" training programme

\section{Statistical procedures}

Many of the participants worked across several wards, and it was therefore deemed unfeasible to consider wards as units for analysis. The sample was therefore analysed as one population.

For analysis of pre-post change on total scores of the CODE and KIDE scales, the Wilcoxon signed-rank test was used because the change score was not Normally distributed. For analysis of pre-post change on total scores of the controllability beliefs scale, we used a paired samples $t$ test as the change scores from this questionnaire were approximately Normally distributed. Each outcome measure was treated as independent of the others. The alpha level was set at 0.05 (two-sided test) for all analyses, and $p$ values of less than or equal to 0.05 were considered statistically significant.

Change on individual items on the CODE scale was measured using a Wilcoxon signed-rank test because the scale contains ordinal data. Change on individual items on the KIDE scale was measured by examining crosstabulations and by undertaking McNemar tests. These tests were selected as the KIDE contains binary data.

Baseline performance on the controllability beliefs scale was compared between those who completed the training and those who dropped out using an independent-samples $t$ test.

An effect size of above 0.30 was considered clinically significant, and effect sizes of 0.10 0.30 were considered as approaching clinical significance. These cut-points are consistent with effect sizes reported for staff training interventions. Effect sizes for Wilcoxon signed- 
The "Getting to Know Me" training programme

rank tests were calculated using the formula $r=z / V n$, and for the paired samples $t$ test the formula $r=v\left(t^{2} /\left(t^{2}+d f\right)\right)$ was used (Field, 2005).

\section{Sample size and power}

Power was calculated based on published psychometrics of the controllability beliefs scale which reports a mean of 49.47 and a standard deviation of 12.96 (Dagnan et al. 2004). Assuming a medium level of correlation $r=0.30$ (Cohen, 1992) between values of the primary outcome before and after the intervention, and the same standard deviations before and after, using a two-sided paired $t$ test at significance level 0.5 and $80 \%$ power, the calculated sample size needed for our study in order to detect a change of five (or an effect size of 0.33) was 76. In order to allow for attrition, our recruitment aim was 125 participants.

\section{The intervention}

The development of the "Getting to Know Me" training programme was led by one author $(S B)$, with support from other members of the author team (RE, JK, JG, PG, \& RC). The design of the programme was informed by existing literature and by identifying staff needs through the use of focus groups, and was developed to produce a package appropriate in content and method of delivery for general hospital staff. Figure 1 provides an overview of the approximate six-hour training programme and its materials. The training was designed to be delivered flexibly; in the current study it was delivered in four sessions each of 45-90 minute duration. The sessions were delivered by three of the authors (SB, JG, \& PG), and an 
The "Getting to Know Me" training programme

additional four members of staff from the hospital where the training was undertaken. The background of the training team was nursing, social work, and medical.

INSERT FIGURE 1 ABOUT HERE

\section{Results}

\section{Participant characteristics}

All participants who attended the first training session of the "Getting to Know Me" programme consented to take part in the study and completed questionnaires at time point one. A total of one hundred and fifteen participants were recruited into the study, and their data were used for psychometric data analysis undertaken on the KIDE and CODE scales. Of this sample, $41 \%(n=47)$ were nurses, $15 \%(n=17)$ were foundation year 1 doctors, $15 \%$ $(n=17)$ were physiotherapists or occupational therapists, and $11 \%(n=13)$ were health care assistants. Seventy-three percent of participants were female.

Attrition rate between time points one and two was 37\%, giving a total of 72 participants who completed the training programme and were eligible for pre-post data analysis. Of this sample, $30 \%(n=21)$ were nurses, $24 \%(n=17)$ were physiotherapists or occupational therapists, $14 \%(n=10)$ were foundation year 1 doctors, and $9 \%(n=6)$ were health care assistants. Seventy six percent were female, and the median length of time employed within health services was six years. Fifty two percent of this sample said they had received no training in dementia care. Thirty seven percent said they had received some training; of 
The "Getting to Know Me" training programme

these, $10 \%$ stated they had a good amount of knowledge, and 3\% reported a high level of specialist training (eg. a degree level course). From the 72 participants, 64 attended all four training sessions, 1 attended three sessions, and 2 attended two sessions. The attendance rate of five participants was not recorded. Of note, the study was slightly underpowered (recruitment target $=76$ ). However, the difference between the recruitment target and actual recruitment $(n=4)$ is well within the range of uncertainty in the estimates of parameters used in sample size calculation.

\section{Questionnaire development}

The 9-item CODE scale and the 16-item KIDE scale are presented in Tables 1 and 2 respectively. Items on which staff demonstrated the least confidence and knowledge were deemed to be of most interest; items are therefore presented in rank order from least confidence/knowledge to greatest confidence/knowledge. KMO if item deleted and Cronbach's alpha if item deleted are presented for each item. This demonstrates that removal of any of the items would not have significantly changed the KMO and Cronbach's alpha for each scale. There was therefore no justification for removing any of the retained items.

Based on initial responses on the CODE scale, our current interpretation of the cut-off points within the scale are as follows: $0-18=$ not confident, $19-35=$ somewhat confident, $36-45=$ very confident. Table 3 depicts the numbers of staff members that fell within each of these categories pre and post-training. 
The "Getting to Know Me" training programme

INSERT TABLE 1 ABOUT HERE

INSERT TABLE 2 ABOUT HERE

\section{Pre-post analysis}

Staff who completed the study did not differ significantly from those who dropped out. Prepost analysis on total CODE scores $(n=62)$ revealed that confidence levels were significantly higher immediately after the training (Median $=35.0$ ) than immediately before the training (Median = 29.0), $z=-6.13 p<0.001$ (Wilcoxon), with effect size $r=-0.56$. The median difference was six, and the $95 \%$ bootstrap $\mathrm{Cl}$ for the median was $[4,6.5]$ using the BCa method (adjusted bootstrap percentile). This suggested that staff confidence in working with people with dementia had increased following the training sessions, and interpretation consistent with other research indicates this is meaningful change (Galvin et al., 2010).

INSERT TABLE 3 ABOUT HERE

Pre-post analysis on total KIDE scores $(n=60)$ revealed that levels of knowledge were significantly higher immediately after the training (Median $=15.0$ ) than immediately before the training (Median = 13.0), $z=-4.81 p<0.001$ (Wilcoxon), with effect size $r=-0.44$. The median difference was small at 1 , and the $95 \%$ bootstrap $\mathrm{Cl}$ for the median was $[0,1]$. This 
The "Getting to Know Me" training programme

suggested that staff knowledge of dementia had improved following the training sessions, and in line with research within this area this is interpreted as a borderline meaningful change (Galvin et al., 2010; Rapp et al., 1998).

A comparison of total scores on the controllability beliefs scale $(n=72)$ immediately before the training (mean=27.96, $s d=8.09)$ and immediately after the training (mean=25.85, $s d=7.90$ ) revealed that there was a significant decrease in scores in the post-training condition ( $t=-3.14 \mathrm{df}=71 \mathrm{p}=0.003, \mathrm{t}$-test) with an effect size $\mathrm{d}=0.37(=3.01 / 8.16)$. The mean and standard deviation we used for the sample size calculation for a paired difference was 5 and 15.3 respectively, so the study achieved greater precision in its estimates than expected. This result also pointed to staff holding a more person-centred perspective on challenging behaviour following the training, however, based on our a priori definition of a clinically meaningful change we would suggest that this result is encouraging rather than indicative of meaningful change.

Items from the CODE scale on which staff demonstrated the poorest confidence and from the KIDE scale on which they demonstrated poorest knowledge (defined by the number of staff who scored an item incorrectly) were deemed to be of particular interest. On the CODE scale, change in confidence was highly significant on items one and two $(p<0.001)$ with effect sizes $r=-0.70$ and $r=-0.59$ respectively. In line with interpretations made on the whole scale, we would suggest that changes on these individual items are indicative of clinically meaningful change. Change on items one and five on the KIDE scale was highly significant $(p<0.001)$, however, knowledge on item four did not change significantly $(p=0.63)$. 
The "Getting to Know Me" training programme

\section{Discussion}

This paper has presented the "Getting to Know Me" training programme which is designed for use with general hospital staff who come into contact with people with dementia. The study comprises the evaluation of the current version of the training programme, together with initial psychometric properties for two new self-report outcome measures: the CODE and KIDE scales.

Seventy-two acute hospital staff were trained using the "Getting to Know Me" programme. Following the programme, confidence in working with people with dementia increased. In addition, knowledge in dementia increased, and beliefs about challenging behaviour shifted towards a more person-centred perspective on behaviours that challenge, however, these shifts were relatively small.

The CODE and KIDE scales both have good internal consistency, face validity, and content validity. Changes in scores on the scales suggested that staff knowledge and confidence had improved. This was in line with the hypotheses of the study, indicating that change measured was in the predicted direction. This gives initial indications that both questionnaires have good criterion validity. Factor analysis was not undertaken on the CODE and KIDE scales due to insufficient numbers. However, further questionnaire data is currently being collected through ongoing studies by the author team, and further analysis (including a factor analysis) will be undertaken in due course. It is hoped that the KIDE and CODE scales will be of benefit. A recent review of 'knowledge of dementia' outcome measures identified a range of limitations with current measures, including weaknesses in psychometric properties and out of date items (Spector, Orrell, Schepers and Shanahan, 
The "Getting to Know Me" training programme

2012), however, other measures of knowledge and confidence for use in this area are also currently being developed (eg. Schepers, Orrell, Shanahan, and Spector, 2012).

Before the training programme, as measured by the CODE scale, average confidence levels fell within the 'somewhat confident' category. Levels increased significantly following the training, and based on our initial interpretations of the scale, average post-training confidence levels were within one point of the 'very confident' category. This is encouraging, and suggests that the changes that occurred were meaningful changes in confidence.

Of note, $52 \%$ of participants reported that they had received no prior training in dementia care. On one level, this is not surprising given national figures published regarding this (Royal College of Psychiatrists, 2011). However, it is clearly a matter of concern given the proportion of patients with dementia in general hospitals, and recent guidance highlights that it is in the interest of all NHS Trusts to deliver dementia training (Department of Health, 2012). Regarding specific areas within dementia training that may be of importance, results from the current study suggest that knowledge and confidence in the areas of communication and managing anger/agitation should be key elements of training.

Our study contains examples of the challenges that arise when implementing a large-scale training programme within the NHS. Our attrition rate was quite high due to difficulty with the release of staff. A one-day course rather than several shorter sessions may have improved the success of the training. When training is being undertaken with staff who have little training in dementia care, outcomes may be enhanced by delivery to a maximum number of staff within a limited time period, followed by supervision on issues arising from 
The "Getting to Know Me" training programme

the training. It is likely that ongoing supervision is paramount to enabling the transfer of knowledge into practice.

It has not been within the scope of this paper to report on all data collected for this study; in addition to data reported here, change in staff practice following the "Getting to Know Me" training was evaluated through use of a qualitative questionnaire. This data will be presented in a future paper. However, at present, although there is theory that underpins the argument that staff knowledge and confidence are important (Bandura, 1977; Bandura, Adams and Beyer, 1977), we are largely in unknown territory regarding whether increased knowledge and confidence amongst general hospital staff actually improves patient care. The translation of training into patient outcomes is a complex and challenging issue which requires much more exploration. Future work will also continue to explore the ways in which common principles from specialist dementia care settings can/cannot be applied to acute hospital care (Moyle, Olorenshaw, Wallis and Borbasi, 2008).

\section{Limitations}

One of the limitations of our study was the use of new questionnaires which did not have established psychometric properties. However, the development and use of our own confidence and knowledge scales was due to the paucity of pre-existing tools. Initial analysis of their psychometric properties is promising.

Much of the training was delivered by one author (SB) who played a significant role in the writing of the materials. It is therefore difficult to know whether the impact of the training 
The "Getting to Know Me" training programme

will change when it is taken out of the environment in which it was originally developed, and when it is delivered by a large numbers of trainers. To address this, the programme is currently being implemented and evaluated across wider NHS general hospital settings.

The present paper reports only on the immediate impact of the "Getting to Know Me" training programme. In order to explore the sustainability of the training, data from twomonth and one-year follow-up time points will be presented in future publications.

\section{Conclusion}

Overall, the "Getting to Know Me" programme was well-received. The results of the study are encouraging, and suggest that the "Getting to Know Me" programme may impact on staff confidence and knowledge. The training programme materials are available for free download and use within the NHS (http://www.gmhiec.org.uk). Following the use of the training programme within Greater Manchester, discussions are ongoing regarding development of the programme to be used in other care settings. Our findings add to a growing evidence-base which can be strengthened by further robust studies, the exploration of the impact of staff training on direct patient outcomes, and further identification of ways in which to transfer principles of care from specialist dementia environments into general hospital settings. 
The "Getting to Know Me" training programme

\section{Acknowledgements}

Advisory group: Gwen Ainsworth, Brian Briggs, Malcolm Campbell, Emily Feilding, Ann Johnson, Mike Howorth, Stephanie Jolly, Andrew Powell, Rebecca Wild, and Gillian ZajacRoles.

This study was funded by, and undertaken as part of, the Health Innovation and Education Cluster (HIEC) programme. The HIEC programme was developed to support the delivery of high quality healthcare, provide education and training, promote innovation in healthcare, and lead to adoption of research. One of the main aims of the HIEC programme was to produce sustainable change in practice within the NHS.

\section{Conflict of Interests}

None.

\section{References}

Alzheimer's Society. (2009). Counting the cost: Caring for people with dementia on hospital wards. London: Alzheimer's Society.

Bandurra, A. (1977). Self-efficacy: Toward a unifying theory of behavioral change. Psychological Review, 84, 191-215.

Bandurra, A., Adams, N. E., \& Beyer, J. (1977). Cognitive processes mediating behavioral change. Journal of Personality and Social Psychology, 35, 125-139.

Cavanagh, S. (1997). Content analysis: concepts, methods and applications. Journal of Nursing Research, 4(3), 5-16.

Cohen, J. (1992). A power primer. Psychological Bulletin, 112(1), 155-159.

Cowdell, F. (2010). The care of older people with dementia in acute hospitals. International Journal of Older People's Nursing, 5(2), 83-92.

Dagnan, D., Grant, F., McDonnell, A. (2004). Understanding challenging behaviour in older people; The development of the controllability beliefs scale. Behavioural and Cognitive Psychotherapy, 32, 501-506.

Davison, T. E., McCabe, M. P., Visser, S., Hudgson, C., Buchanan, G., \& George, K. (2007). Controlled trial of dementia training with a peer support group for aged care staff. International Journal of Geriatric Psychiatry, 22(9), 868-873. 
Department of Health (2009). Living well with dementia: A national dementia strategy. Retrieved 15 June 2010 from http://www.dh.gov.uk/prod consum dh/groups /dh digitalassets/@dh/@en/documents/digitalasset/dh_094051.pdf

Department of Health (2010). Quality outcomes for people with dementia: Building on the work of the National Dementia Strategy. Retrieved 25 September 2012 from http://www.dh.gov.uk/prod consum dh/groups/dh digitalassets/@dh/@en/@ps/docume nts/digitalasset/dh 119828.pdf

Department of Health (2012). Using the commissioning for quality and innovation (CQUIN) payment framework: Guidance on new national goals for 2012-13. Retrieved 19 August 2013 from http://media.dh.gov.uk/network/231/files/2012/05/CQUINN-safetythermometer-guidance.pdf

Douglas-Dunbar, M., \& Gardiner, P. (2007). Support for carers of people with dementia during hospital admission. Nursing Older People, 19(8), 27-30.

Field, A. (2005). Discovering statistics using SPSS. London: Sage Publications.

Fossey, J., Ballard, C., Juszczak, E., James, I., Alder, N., Jacoby, R., \& Howard, R. (2006). Effect of enhanced psychosocial care on antipsychotic use in nursing home residents with severe dementia: cluster randomised trial. British Medical Journal, 332(7544), 756-761.

Galvin, J. E., Kuntemeier, B., Al-Hammadi, N., Germino, J., Murphy-White, M., \& McGillick, J. (2010). "Dementia-friendly hospitals: Care not crisis." An educational program designed to improve the care of the hospitalized patient with dementia. Alzheimer Disease and Associated Disorders, 24(4), 372-379.

Hughes, J., Bagley, H., Reilly, S., Burns, A., \& Challis, D. (2008). Care staff working with people with dementia: training, knowledge and confidence. Dementia, 7, 227-238.

Innes, A. (2000). Training and development for dementia care workers. London: Jessica Kingsley Publishers.

Kuske, B., Hanns, S., Luck, T., Angermeyer, M C., Behrens, J., \& Riedel-Heller, S. G. (2007). Nursing home staff training in dementia care: a systematic review of evaluated programs. International Psychogeriatrics, 19(5), 818-841.

May, H., Edwards, P., \& Brooker, D. (2009). Enhanced care planning for people with dementia: A good practice guide. London: Jessica Kingsley Publishers.

McCabe, M. P., Davison, T. E., \& George, K. (2007). Effectiveness of staff training programs for behavioral problems among older people with dementia. Aging and Mental Health, 11(5), 505-519.

Moniz-Cook, E., Vernooij-Dassen, M., Woods, R., Verhey, F., Chattat, R., DE Vugt, M., Mountain, G., O'connell, M., Harrrison, J., Vasse, E., Dröes, R. M., \& Orrell, M. (2008). A European consensus on outcome measures for psychosocial intervention research in dementia care. Aging and Mental Health, 12, 14-29. 
Morse, J. M., \& Field, P. A. (1995). Qualitative research methods for health professionals (2nd ed.). Thousand Oaks, CA: Sage.

Moyle, W., Olorenshaw, R., Wallis, M., \& Borbasi, S. (2008). Best practice for the management of older people with dementia in the acute care setting: a review of the literature. International Journal of Older People Nursing, 3, 121-130.

National Institute for Health and Clinical Excellence/Social Care Institute for Excellence (2007). Dementia: A NICE-SCIE guideline on supporting people with dementia and their carers in health and social care. NICE clinical practice guideline $\left(42^{\text {nd }}\right.$ ed.). London: Author.

Nunally, J. C. (1978). Psychometric theory (2 ${ }^{\text {nd }}$ ed.). New York: McGraw-Hill.

Pett, M. A., Lackley, N R., Sullivan, J. J. (2003). Making sense of factor analysis. The Use of Factor Analysis for Instrument Development in Health Care Research. London: Sage Publications.

Rapp, C., Onega, L., Tripp-Reimer, T., Mobily, P., Wakefield, B., Kundrat, M., Akins, J., Wadle, K., Mentes, J., Culp, K., Meyer, J., \& Waterman, J. (1998). Unit-based acute confusion resource nurse: An educational program to train staff nurses. Gerontologist, 38(5), 628-632.

Royal College of Psychiatrists (2011). Report of the National Audit of Dementia Care in General Hospitals 2011. Retrieved 7 January 2013 from http://www.rcpsych.ac.uk/pdf/ NATIONAL\%20REPORT\%20\%20Full\%20Report\%201201122.pdf

Schepers, A. (2010). The sense of competence in dementia care questionnaire for staff (SOCID-S): Development, reliability, and validity. Unpublished manuscript, University College London.

Schepers, A. K., Orrell, M., Shanahan, N., \& Spector, A. (2012). Sense of competence in dementia care staff (SCIDS) scale: development, reliability, and validity. International Psychogeriatrics, 24(7), 1153-1162.

Spector, A., Orrell, M., Schepers, A., \& Shanahan, N. (2012). A systematic review of 'knowledge of dementia' outcome measures. Ageing Research Reviews, 11(1), 67-77.

Streiner, D. L., \& Norman, G. R. (2003). Health measurement scales: A practical guide to their development and use ( $3^{\text {rd }}$ ed.). Oxford: Oxford University Press.

Teri, L., Huda, P., Gibbons, L., Young, H., \& van Leynseele, J. (2005). STAR: A dementiaspecific training program for staff in assisted living residences. Gerontologist, 45(5), 686-693.

Zimmerman, S., Williams, C. S., Reed, P. S., Boustani, M., Preisser, J. S., Heck, E., \& Slaone, P. D. (2005). Attitudes, stress, and satisfaction of staff who care for residents with dementia. Gerontologist, 45, 96-105. 
Figure 1: Overview of the training programme and its materials.

Overview of the training materials:

1. Disc 1. DVD containing six PowerPoint presentations, video clips (WMV and MP4 formats), PDFs of the materials contained in the training pack, and disc instructions

2. Disc 2. DVD containing video clips (to play on a computer with a DVD drive or a DVD movie player)

3. Communication skills mini-guide

4. "Getting to Know Me" card. A four-sided patient document to be completed by a person and their family. The card is designed to stand up by the hospital bedside.

5. "Getting to Know Me": Manual for Trainers

6. "Getting to Know Me": Booklet for Staff

7. E valuation form

The main topic areas covered within the programme:

- Dementia, an introduction.

- Seeing the whole person.

- Communication.

- The impact of the hospital environment.

- Knowing the person.

- A person centred understanding of behaviour that challenges. 
The "Getting to Know Me" training programme

Table 1: Psychometric properties for the Confidence in Dementia Scale ( $n=115)$.

\begin{tabular}{|c|c|c|c|c|}
\hline $\begin{array}{l}\text { Rank } \\
\text { order }\end{array}$ & Item $^{a}$ & $\begin{array}{l}\text { Mean } \\
\text { (SD) }\end{array}$ & $\begin{array}{l}\text { KMO if } \\
\text { item } \\
\text { deleted }\end{array}$ & $\begin{array}{l}\text { Cronbach's } \\
\text { alpha if } \\
\text { item } \\
\text { deleted }\end{array}$ \\
\hline 1 & $\begin{array}{l}\text { I feel able to understand the needs of a person } \\
\text { with dementia when they cannot communicate } \\
\text { well verbally }\end{array}$ & $\begin{array}{l}2.58 \\
(0.76)\end{array}$ & 0.86 & 0.90 \\
\hline 2 & $\begin{array}{l}\text { I feel able to interact with a person with } \\
\text { dementia when they cannot communicate well } \\
\text { verbally }\end{array}$ & $\begin{array}{l}2.86 \\
(0.82)\end{array}$ & 0.86 & 0.90 \\
\hline 3 & $\begin{array}{l}\text { I feel able to manage situations when a person } \\
\text { with dementia becomes agitated }\end{array}$ & $\begin{array}{l}3.02 \\
(0.86)\end{array}$ & 0.95 & 0.90 \\
\hline 4 & $\begin{array}{l}\text { I feel able to identify when a person may have a } \\
\text { dementia }\end{array}$ & $\begin{array}{l}3.02 \\
(0.74)\end{array}$ & 0.91 & 0.90 \\
\hline 5 & $\begin{array}{l}\text { I feel able to gather relevant information to } \\
\text { understand the needs of a person with dementia }\end{array}$ & $\begin{array}{l}3.15 \\
(0.89)\end{array}$ & 0.92 & 0.90 \\
\hline 6 & $\begin{array}{l}\text { I feel able to help a person with dementia feel } \\
\text { safe during their stay in hospital }\end{array}$ & $\begin{array}{l}3.37 \\
(0.85)\end{array}$ & 0.88 & 0.90 \\
\hline 7 & $\begin{array}{l}\text { I feel able to work with people who have a } \\
\text { diagnosis of dementia }\end{array}$ & $\begin{array}{l}3.54 \\
(1.00)\end{array}$ & 0.91 & 0.91 \\
\hline 8 & $\begin{array}{l}\text { I feel able to understand the needs of a person } \\
\text { with dementia when they can communicate well } \\
\text { verbally }\end{array}$ & $\begin{array}{l}3.54 \\
(0.86)\end{array}$ & 0.92 & 0.90 \\
\hline 9 & $\begin{array}{l}\text { I feel able to interact with a person with } \\
\text { dementia when they can communicate well } \\
\text { verbally }\end{array}$ & $\begin{array}{l}3.86 \\
(0.85)\end{array}$ & 0.88 & 0.89 \\
\hline
\end{tabular}

${ }^{\mathrm{a}}$ Response range 1-5, not able-very able. 
The "Getting to Know Me" training programme

Table 2: Psychometric properties for the Knowledge in Dementia Scale $(n=115)$.

\begin{tabular}{|c|c|c|c|c|}
\hline $\begin{array}{l}\text { Rank } \\
\text { order }\end{array}$ & Item $^{a}$ & Mean (SD) & $\begin{array}{l}\text { KMO if } \\
\text { item } \\
\text { deleted }\end{array}$ & $\begin{array}{l}\text { Cronbach's } \\
\text { alpha if } \\
\text { item } \\
\text { deleted }\end{array}$ \\
\hline 1 & $\begin{array}{l}\text { Anger and hostility occur in dementia mostly because } \\
\text { the "aggression" part of the brain has been affected" }\end{array}$ & $0.52(0.50)$ & 0.72 & 0.71 \\
\hline 2 & $\begin{array}{l}\text { Dementia is a general term which refers to a number } \\
\text { of different diseases }\end{array}$ & $0.59(0.49)$ & 0.62 & 0.71 \\
\hline 3 & $\begin{array}{l}\text { Dementia can be caused by a number of small } \\
\text { strokes }\end{array}$ & $0.59(0.49)$ & 0.55 & 0.70 \\
\hline 4 & $\begin{array}{l}\text { People with dementia will eventually lose all their } \\
\text { ability to communicate }\end{array}$ & $0.61(0.49)$ & 0.71 & 0.69 \\
\hline 5 & $\begin{array}{l}\text { A person with dementia's history and background } \\
\text { play a significant part in their behaviour }\end{array}$ & $0.65(0.48)$ & 0.68 & 0.71 \\
\hline 6 & $\begin{array}{l}\text { A person with dementia is less likely to receive pain } \\
\text { relief than a person without dementia when they are } \\
\text { in hospital }\end{array}$ & $0.70(0.46)$ & 0.72 & 0.71 \\
\hline 7 & $\begin{array}{l}\text { People with dementia who are verbally aggressive } \\
\text { nearly always become physically aggressive }\end{array}$ & $0.77(0.42)$ & 0.80 & 0.68 \\
\hline 8 & $\begin{array}{l}\text { When people with dementia walk around it is usually } \\
\text { aimless }^{\text {b }}\end{array}$ & $0.79(0.41)$ & 0.63 & 0.70 \\
\hline 9 & $\begin{array}{l}\text { Permanent changes to the brain occur in most types } \\
\text { of dementia }\end{array}$ & $0.79(0.41)$ & 0.55 & 0.71 \\
\hline 10 & $\begin{array}{l}\text { Brain damage is the only factor that is responsible for } \\
\text { the way people with dementia behave }{ }^{b}\end{array}$ & $0.81(0.40)$ & 0.70 & 0.70 \\
\hline 11 & $\begin{array}{l}\text { Physical pain may result in a person with dementia } \\
\text { becoming aggressive or withdrawn }\end{array}$ & $0.86(0.35)$ & 0.72 & 0.71 \\
\hline 12 & $\begin{array}{l}\text { People who have dementia will usually show the } \\
\text { same symptoms }\end{array}$ & $0.86(0.35)$ & 0.66 & 0.70 \\
\hline 13 & Currently, most types of dementia cannot be cured & $0.88(0.33)$ & 0.82 & 0.71 \\
\hline 14 & People with dementia never get depressed ${ }^{b}$ & $0.93(0.26)$ & 0.57 & 0.71 \\
\hline 15 & $\begin{array}{l}\text { My perception of reality may be different from that } \\
\text { of a person with dementia }\end{array}$ & $0.94(0.24)$ & 0.70 & 0.69 \\
\hline 16 & It is possible to catch dementia from other people ${ }^{b}$ & $0.99(0.09)$ & 0.57 & 0.70 \\
\hline
\end{tabular}

${ }^{a}$ Response range 1 or 0 , agree or disagree.

${ }^{\mathrm{b}}$ Items $1,4,7,8,10,12,14, \& 16$ were reverse scored. Thus disagreement with these statements reflected a correct response. 
The "Getting to Know Me" training programme

Table 3: Number of staff who fell within (preliminary) categories within the CODE scale.

\begin{tabular}{|l|l|l|}
\hline Category & Pre-training & Post-training \\
\hline Not confident & $3(5 \%)$ & $1(2 \%)$ \\
\hline Somewhat confident & $51(82 \%)$ & $32(52 \%)$ \\
\hline Very confident & $8(13 \%)$ & $29(47 \%)$ \\
\hline
\end{tabular}

